\section{Better pay for UK students?}

\section{London}

Traditional ways of postgraduate student support in Britain have been undermined by a new scheme launched by the Wellcome Trust, a private charity. The scheme awards students a much more generous stipend than that offered by the state-funded research councils.

The Wellcome Trust, whose funds for the support of basic medical research were substantially increased last year by the sale of a third of its shareholding in the Wellcome Foundation, the drug company, has begun supporting graduate students in the belief that support by the research councils is now inadequate. The trust plans to spend $£ 1$ million on 30 studentships over the next three years.

The value of a Wellcome stipend will be $£ 4,000$, with additional funds of up to $£ 2,000$ for expenses. This puts the

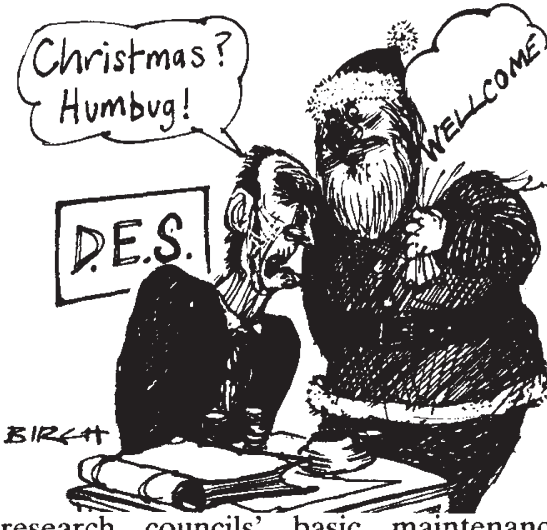

research councils' basic maintenance grant of just over $£ 2,700$ in a very poor light. The Trust says that the value of the research councils' stipend is now so low that promising students are deterred from considering an academic career. The Medical Research Council (MRC) now has a chronic shortage of graduate students (see Nature 330, 595; 1987).

Far from being an embarrassment, MRC says that the initiative is welcome. The research councils are now considering whether to raise the level of support to meet Wellcome's challenge. To do this, the MRC would need to inject $£ 2.2$ million per year into its postgraduate support programme to maintain student numbers at present levels. If it does not follow suit, the coexistence of research council and Wellcome students would inspire "a degree of tension" in laboratories, says Barton Dodd of the MRC.

Even though the Wellcome scheme will cream off about 15 per cent of the annual graduate intake into the biomedical sciences, neither Wellcome nor MRC sees the scheme as a threat to the dominance of the research councils in postgraduate support.

\title{
British ocean research looks to its long-term future
}

\section{London}

THE British Natural Environment Research Council (NERC) has set as one of its objectives "to predict the oceans", according to Dr John Woods, director of marine sciences at the research council, describing last week NERC's plans for marine research.

At the same time, NERC which is the chief source of funds for geophysical research in Britain seems to be aware that it may be "taking a risk" in advertising such a long-term goal when the government is asking for the solution of practical problems and when it is itself caught in a financial crisis (see Nature 329, 96; 1987).

NERC says it is determined to convince the authorities of the need for long-term research, but support also comes from last year's House of Lords report on marine science, which called for closer coordination of government spending. NERC has agreed to provide the secretariat for the new Coordinating Committee for Marine Science and Technology, the centrepiece of the government's response to the House of Lords.

Woods likens oceanography to meteor- ology, saying that oceanographers need computer models of oceanic circulation comparable with those now used by weather forecasters. He believes there will be sufficient computer power in twenty years to support the more exacting demands of oceanography.

NERC is therefore supporting the development of high-resolution oceanographic models and the technology of data-gathering using unmanned deep ocean vehicles as well as remote sensing from satellites and acoustic sensors.

Given financial uncertainties, NERC is planning a core programme in marine science and a menu of options to be carried out if funds are available. In the core are a plan to model the North Sea the better to predict the transport of pollutants and a project to construct a fineresolution model of the Southern Ocean.

A project to develop two types of unmanned submersibles (under the name of AUTOSUB) should yield data of a novel character from the deep oceans, but NERC is also committed to studies of the geochemistry and global circulation of the oceans.

\section{Troublesome trials for AIDS vaccines}

\section{Washington}

The first US clinical trial of a vaccine against AIDS (acquired immune deficiency syndrome) is having difficulty finding enough suitable volunteers. The trial administered by the US National Institutes of Health (NIH) using recombinant gp160 protein produced by the biotechnology company MicroGeneSys - began in October. But so far, only 26 volunteers out of the required 81 have been found for the programme, raising fears for the future of AIDS vaccine testing.

Frank Volvovitz, president of MicroGeneSys, says that hundreds of male homosexuals came forward for the trial, but most were rejected for medical reasons such as hypertension. Others dropped out because of the time commitment required.

Volvovitz says the dearth of participants in the trial is partly attributable to volunteers' reluctance to become seropositive for HIV (human immunodeficiency virus), the virus that causes AIDS. Although blood from volunteers will test positive for HIV after vaccination, a Western blot test routinely performed to screen out false positives - would prove that the person had not actually been infected with the virus. Further, the NIH will issue certificates to those who participate in the trial, to prevent discrimination against them on the basis of seropositivity. The present trial is meant to test only safety and immunogenicity. Later, much larger groups will be needed to assess the vaccine's efficacy.

Gerald Quinnan, head of virology at the US Food and Drug Administration, said that an "endpoint" other than the diagnosis of AIDS should be found to indicate the failure of a vaccine. The long incubation period of AIDS means waiting for years to see if subjects are protected from inadvertent exposure to the virus.

Quinnan also pointed out that the number of homosexual males in the United States will not be large enough to support the widespread testing of multiple vaccines, and new study populations will need to be investigated.

As the availability of study populations tightens, developed countries may be tempted to look at poorer countries as places for testing vaccines. The World Health Organisation (WHO) has formed a committee on vaccines as part of its new AIDS programme to help less-developed countries decide among the many proposals for testing AIDS vaccines with which they are likely to be presented.

Sir James Gowans, chairman of the committee, says the WHO should be able to provide an independent assessment, and although the body has no regulatory power it would use "moral force" to prevent exploitation.
Carol Ezzell 